University of Nebraska - Lincoln

DigitalCommons@University of Nebraska - Lincoln

1996

\title{
Extracting ecological and biophysical information from AVHRR optical data: An integrated algorithm based on inverse modeling
}

\author{
B. H. Braswell \\ University of New Hampshire \\ D. S. Schimel \\ National Center for Atmospheric Research \\ J. L. Privette \\ University of Maryland \\ B. Moore III \\ University of New Hampshire \\ W. J. Emery \\ University of Colorado
}

See next page for additional authors

Follow this and additional works at: https://digitalcommons.unl.edu/nasapub

Part of the Physical Sciences and Mathematics Commons

Braswell, B. H.; Schimel, D. S.; Privette, J. L.; Moore III, B.; Emery, W. J.; Sulzman, E. W.; and Hudak, A. T., "Extracting ecological and biophysical information from AVHRR optical data: An integrated algorithm based on inverse modeling" (1996). NASA Publications. 30.

https://digitalcommons.unl.edu/nasapub/30

This Article is brought to you for free and open access by the National Aeronautics and Space Administration at DigitalCommons@University of Nebraska - Lincoln. It has been accepted for inclusion in NASA Publications by an authorized administrator of DigitalCommons@University of Nebraska - Lincoln. 


\section{Authors}

B. H. Braswell, D. S. Schimel, J. L. Privette, B. Moore III, W. J. Emery, E. W. Sulzman, and A. T. Hudak 


\title{
Extracting ecological and biophysical information from AVHRR optical data: An integrated algorithm based on inverse modeling
}

\author{
B. H. Braswell, ${ }^{1,2}$ D. S. Schimel, ${ }^{2}$ J. L. Privette, ${ }^{3}$ B. Moore III, \\ W. J. Emery, ${ }^{4}$ E. W. Sulzman, ${ }^{2}$ and A. T. Hudak ${ }^{5}$
}

\begin{abstract}
Satellite remote sensing provides the only means of directly observing the entire surface of the Earth at regular spatial and temporal intervals. Key Earth system variables can be obtained from satellite data by integrating appropriate processing, interpretation, and modeling. For example, the amount of photosynthetically active radiation absorbed by plants (APAR) and land surface albedo can be inferred from remotely sensed optical measurements. Radiative transfer model inversion exploits the dependence of reflectance on the relative source-sensor geometry to estimate surface parameters. In contrast, geometrical effects are suppressed in most other approaches. We present an algorithm for the retrieval of fractional APAR (fAPAR), albedo, and other parameters from AVHRR (advanced very high resolution radiometer) reflectance measurements by inverting a modified version of the SAIL (scattering by arbitrarily inclined leaves) canopy radiative transfer model. The model is inverted using an effective bidirectional reflectance factor (BRF) distribution created by aggregating AVHRR data into cells of size comparable to those used in current terrestrial biosphere models $(50 \times 50 \mathrm{~km})$. Successful inversion results over an area in central Africa are presented and compared with a vegetation index-based analysis and other satellite data. The procedure also provides unique information on phenology derived from timing of changes in leaf optical properties and canopy structure. Our methods are unique in that they explicitly incorporate a priori ecological knowledge in the choice of model parameters and constraints. This approach can eventually be employed at pixel resolution with the EOS sensors, MODIS (moderate-resolution imaging spectrometer) and MISR (multiangle imaging spectro-radiometer).
\end{abstract}

\section{Introduction}

\section{Background}

The terrestrial biosphere plays an important role in regulating the interaction between climate and global biogeochemical cycles, especially on interannual-to-decadal timescales [Sellers et al., 1992; Schimel, 1995]. Indeed, a great deal of the uncertainty in the response of the Earth system to human perturbations hinges on an understanding of the behavior of terrestrial ecosystems. This is due primarily to the coupling of the global carbon cycle to the Earth's radiation budget, and to the complexity of terres-

\footnotetext{
${ }^{\mathrm{I}}$ Institute for the Study of Earth, Oceams, and Space, University of New Hampshıre, Durham.

${ }^{2}$ National Center for Atmospherıc Research, Boulder, Colorado.

${ }^{3}$ Department of Geography, University of Maryland, College Park.

${ }^{4}$ Colorado Center for Astrodynamıcs Research, Unıversity of Colorado, Boulder.

${ }^{5}$ Center for the Study of Earth from Space, University of Colorado, Boulder.
}

Copyright 1996 by the Amerıcan Geophysical Union.

Paper number 96JD02181

0148-0227/96/96JD-02181\$09.00 trial processes that govern biosphere-atmosphere exchange of $\mathrm{CO}_{2}$, water, and energy. Process models can be used in concert with field observations to represent the dynamics of terrestrial systems, alone, or coupled to a climate model. Few of these models, however, are designed to accurately predict spatial and interannual variability.

Satellite remote sensing instruments such as the AVHRR (advanced very high resolution radiometer) [Kidwell, 1991] are potentially powerful tools for constraining modeled spatial and temporal patterns of land surface interactions with the atmosphere. The links between modeling and remote sensing are primarily associated with calculations of plant production and of the energy budget. Ecosystem net primary productivity (NPP) may be estimated from optical measurements (e.g., by the AVHRR) because of the biophysical nature of photosynthesis; actively photosynthesizing leaves have a unique spectral signature, exhibiting high absorptance in the visible wavelengths $(0.4-0.7 \mu \mathrm{m})$ and high reflectance in the near-infrared wavelengths $(0.7-$ $1.2 \mu \mathrm{m})$. This signature (Plate 1 ) is enhanced or modified by the architecture and physiological status of the plant canopy. Water and energy exchanges are, in part, a function of the total solar energy that is absorbed by the land surface. Albedo, the fraction of solar energy that is not absorbed, can also be determined using remote observations of reflected solar radiation in the visible and near-infrared wavelengths. 


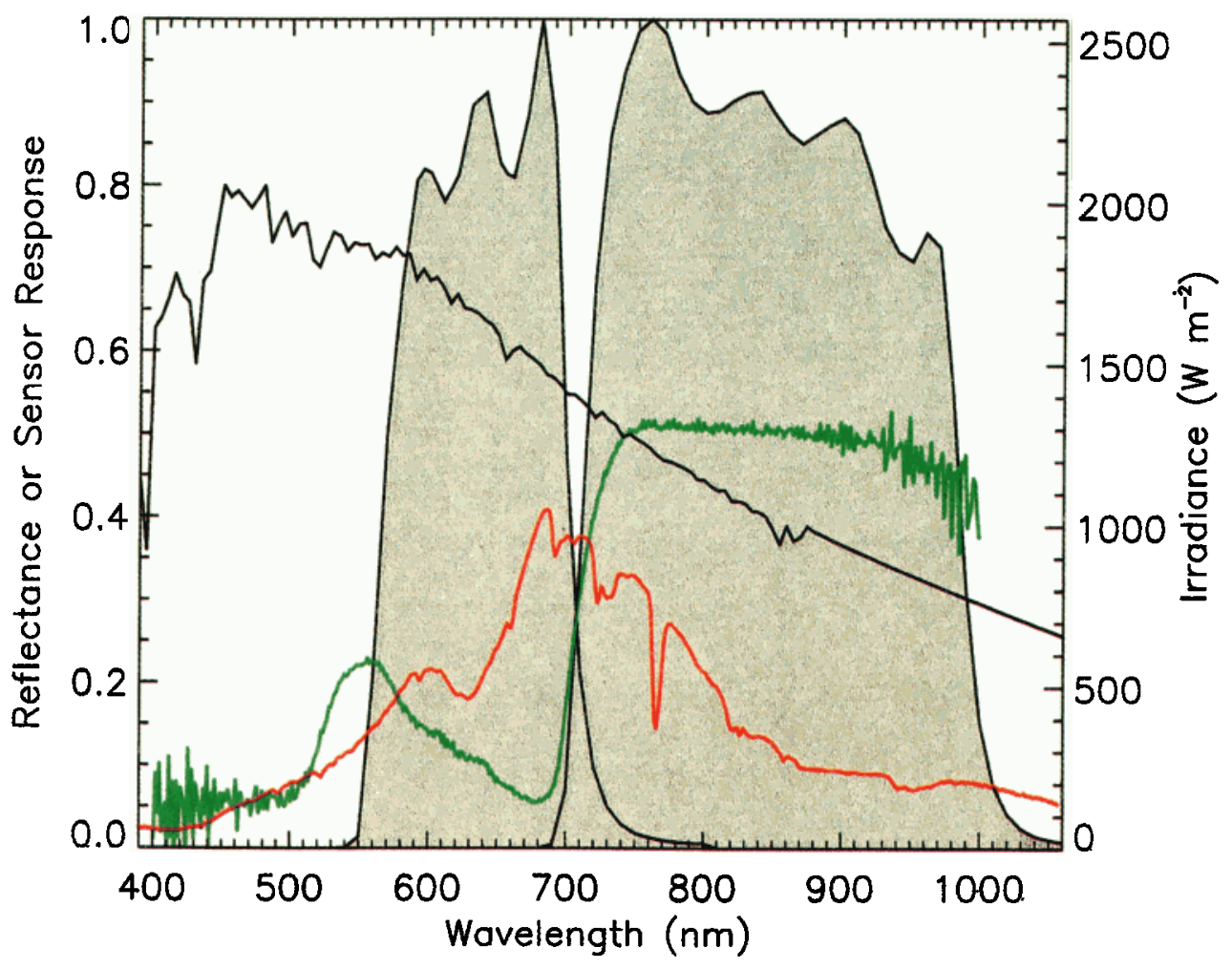

Plate 1. Typical leaf (green line) and soil (red line) reflectance spectra, the advanced very high resolution radiometry (AVHRR) visible and near infrared (NIR) sensor response curves (gray regions), and the solar spectrum (black line).

\section{Interpretation of Remotely Sensed Data}

To obtain information about vegetation structure and function from remote sensing, a model is needed to convert the signal measured by the satellite sensor (reflected solar radiation) into variables that are meaningful at the stand or ecosystem level. One approach is to use empirical models that relate algebraic combinations of spectral reflectances, known as vegetation indices (VI), with the ecological or biophysical variable of interest. One of the most widely used indices is the normalized difference vegetation index (NDVI), which is the difference between the reflectance measured in the red and near-infrared channels divided by their sum. There is a theoretical and experimental basis for the relationship between NDVI and a number of ecosystem variables, including canopy photosynthetic efficiency, absorbed photosynthetically active radiation, and stomatal conductance [e.g., Asrar et al., 1984; Running et al., 1989; Myneni et al., 1992b; Sellers et al., 1992]. Also, there is a nonlinear relationship with leaf area index (LAI), approaching an asymptotic value at moderate to high values of LAI (generally for LAI $>3$ ).

The use of remotely sensed vegetation indices as a direct proxy for surface variables, however, ignores some important dependencies, even when atmospheric corrections have been applied to the data. Predominately, these are the effects of solar and viewing geometry and the effects of variable background reflectance. Moreover, because of its asymptotic dependence, NDVI can be used to infer LAI only over a limited range of LAI. Although the relationship between NDVI and fAPAR is generally linear, it is wellknown to be sensitive to the status of many soil-vegetation- atmosphere system parameters that exhibit high spatial and/or temporal variability [Goward and Huemmrich, 1992]. Thus, a one-to-one relationship between a VI and a biophysical variable may not be generally applicable, except through careful consideration of complicating factors; by inventing indices that are less sensitive to atmospheric or soil influences [Huete, 1988; Pinty and Verstraete, 1992], by normalizing the index [Roujean and Breon, 1995], or by selecting pixels with preferred view angles [Cihlar et al., 1994]. Such considerations (especially the latter two) potentially involve the use of radiative transfer (RT) models, approaching in a technical sense the method of inversion.

Inverse modeling uses physical models of the radiation regime within a plant canopy to retrieve information about the surface. Specifically, models are required that simulate plant canopy reflectance given a unique parameterization of the structural and optical characteristics of vegetation components. In this approach, an optimization scheme is used to calculate the parameter set that yields modeled reflectance most consistent with the observed reflectance data. Radiative transfer models vary in complexity from empirical techniques [Walthall et al., 1985] that require only a few parameters and represent highly idealized canopies, to three-dimensional discrete ordinates methods [Myneni et al., 1992a] that account for all known scattering processes but require a large number of parameters. The inversion technique is analogous to solving $N$ equations with $M$ unknowns; in order to retrieve $M$ parameters we need the equivalent of $N \geq M$ independent observations of the target. Therefore, there is an inherent compromise between model 
complexity, the number of measurements of a given target, and accuracy of parameter retrieval.

Radiative transfer model inversion has a number of distinct advantages over other approaches: it is physically based, so that the relationship between measured reflectance and surface biophysics is self-adjusting instead of empirically calibrated, it deals with mechanisms that would otherwise contaminate the signal, and it allows the researcher to incorporate ecological knowledge and field measurements in a consistent way. The degree to which the model physics (assuming they are adequately represented) adjust to novel environments depends on the quality of ancillary ecological information provided, but the retrieved parameters should not be less accurate those derived from methods that do not incorporate such data. The main disadvantage of inversion is that it is computationally more intensive. The requirement of multiple measurements may be considered a disadvantage, but we will demonstrate a practical solution to that problem.

The objectives of this paper are (1) to present an algorithm for the retrieval of land surface information over large areas using a physical model and a global optical data set, and (2) to present initial results that demonstrate the potential for this algorithm to be used operationally. Past RT model inversions have been limited to point analyses. We extend these efforts by developing a technique that facilitates inversions at regional to global scales. Our method works with the AVHRR Pathfinder product, which is readily available, and the only current global reflectance data set suitable for this use.

\section{The AVHRR Pathfinder Data Product}

Since 1981, optical reflectance data has been gathered from the AVHRR on board the NOAA 7 through 11 polar orbiting platforms. This instrument measures exiting radiance in five channels: red $(0.58-0.68 \mu \mathrm{m})$, near-infrared (NIR; 0.73-1.10 $\mu \mathrm{m}$ ), and three in the thermal infrared. These satellites approximately cover the globe each day, and the highest spatial resolution possible is about $1.1 \times 1.1$ $\mathrm{km}$. The Pathfinder AVHRR Land (PAL) product [ $\mathrm{Agbu}$ and James, 1995] is a global data set, with $8 \times 8 \mathrm{~km}$ spatial resolution and a 10-day compositing interval. The data are projected onto a Goode's Homolosine equal-area map base. There are 12 data layers; each pixel contains the two optical reflectances $\left(\mathbf{R}^{*} \lambda_{1}\right.$ and $\left.R^{*} \lambda_{2}\right)$, temperatures from the three thermal bands, sun and sensor zenith angles $(\theta$ and $\theta^{\prime}$ ), the relative azimuth angle $(\psi)$, and the day/hour of observation. Also included is a quality control (QC) flag, an estimate of the extent of cloud contamination calculated using the thermal bands, and NDVI. The QC and cloud flag layers are described in detail in work by Agbu and James [1995] and are used in our algorithm to filter pixels that potentially contain errors or extensive cloud contamination.

The Pathfinder reflectances are derived from the "global area coverage" (GAC) data that are produced on board the satellite. Because of on-board data storage limitations, the nominal $1.1 \mathrm{~km}$ "local area coverage" (LAC) spatial resolution of AVHRR is not automatically retained for the entire globe. Instead, measurements are aggregated by averaging four adjacent samples out of every five in a scan line, then skipping the next two scan lines [Kidwell, 1991].
The resulting GAC spatial resolution is approximately $1 \times 4$ $\mathrm{km}$ at nadir. In the Pathfinder data set, pixels are mapped on to a global grid from the raw GAC data. Global area coverage data has coarser resolution and potentially poorer quality than the $1.1 \mathrm{~km} \mathrm{LAC}$ data because of reduced spatial sampling, but logistical issues associated with recovering LAC measurements are being addressed by an International Geosphere Biosphere Program core project [Townshend et al., 1994] and global "1 km AVHRR" data will soon be available for a limited time domain, including the ancillary information (described above) that is necessary for our analysis.

The data are temporally composited (during Pathfinder processing) by choosing the $\mathrm{GAC}$ reflectances and the associated ancillary information from the observation that yielded the highest NDVI in the 10-day window, a common practice because almost all factors (particularly aerosols and water vapor) that contaminate the signal from the land surface tend to reduce NDVI [Holben, 1986]. Bidirectional effects on NDVI are a complex function of sun-sensor geometry and land surface conditions and thus they will not be selected out of the data by this compositing technique. Moreover, the compositing process has the effect of increasing the sampling of sun-sensor geometry from pixel to pixel because the uncorrected atmospheric effects that lead to decreased NDVI tend to be spatially and temporally heterogeneous, and because each consecutive overpass will have a unique (random) scan angle. Thus, it is very likely that nearby pixels in the product are derived from different overpasses. This effect of compositıng on the local distribution of sun-sensor angles facilitates the application of the method introduced in this paper.

The PAL global data product currently covers 19811994 (see also WWW site http://xtreme.gsfc.nasa.gov). In our analysis we have used two subsets of the data for two related applications. First, an initial large-scale stratification and geostatistical description was performed using all of the 10-day composited data for the African contınent for the years 1986-1988. Second, for the set of inversion experıments, we extracted clusters of pixels (cells) along a transect in central Africa for all 12 months of 1986.

\section{Theoretical Background}

Spaceborne radiometers (e.g., AVHRR) measure solar radiation that has been transmitted through the atmosphere, interacted with the surface (including vegetation, soil, water, etc.), and then transmitted back through the atmosphere to the satellite. A radiometer measures the photon energy flux received within fixed intervals of wavelength and solid angle. This information can be translated into reflectance, a physical variable that is independent of instrument characteristics and solar flux, through radiometric calibration [Brown et al., 1985]. The variation of reflectance with respect to wavelength and sun-sensor geometry is called the bidirectional reflectance factor (BRF) and is given by

$$
R\left(\mathbf{r}, \mathbf{r}^{\prime}, \lambda\right)=\frac{\pi L\left(\mathbf{r}, \mathbf{r}^{\prime}, \lambda\right)}{E_{s}\left(\mathbf{r}^{\prime}, \lambda\right)},
$$

where $E_{s}$ is the solar irradiance (watts per squared meter) incident from the $\mathbf{r}^{\prime}$ direction, and $L$ is the outgoing radi- 
ance (watts per squared meter per steradian) measured at $\mathbf{r}$. This is an approximate expression because there is usually a small flux of radiation incident from all directions ("skylight") in addition to the direct solar beam.

Canopy radiative transfer models simulate the BRF for a given wavelength band as a function of sun-sensor geometry, and a set of parameters $\mathbf{P}$ describing the architectural and optical characteristics of the components for the vegetated surface, that is, $R=R_{\mathbf{p}}\left(\mathbf{r}, \mathbf{r}^{\prime}, \lambda\right)$. In this study, we used the SAIL (scattering by arbitrarily inclined leaves) model [Verhoef, 1984, 1985] because it is intermediate in complexity, and represents a compromise between physical realism and the number of input parameters. Parameters of the SAIL model include leaf area index (LAI), leaf optical properties, and leaf angle distribution. The SAIL model calculates $R_{\mathbf{P}}$ by solving the radiative transfer equations for scattering of diffuse and direct sunlight by a distribution of small flat elements (leaves) in a semi-infinite medium.

We have modified SAIL to simulate the reflectance of two-component canopies [cf., Qin, 1993], including a hot

We have modified SAIL to simulate the reflectance of two-component canopies [cf., Qin, 1993], including a hot spot parameterization [Kuusk, 1991] for both components. Table 1 shows the full set of parameters used in this implementation of the model (SAIL-2). It is important to represent nonphotosynthetic vegetation (NPV) components in a radiative transfer model because almost all plant canopies contain stems, standing dead, or senescent leaves that interact with radiation and affect estimates of physical parameters. For example, fully senescent grasslands in the dry season can absorb a significant amount of radiation in the PAR wavelengths that is not associated with biological ac- tivity. The hot spot parameterization allows for the treatment of self-shading effects of both components; when the observer is looking from the backscatter direction, fewer shadows are seen than from the forward scatter direction, leading to greater observed radiance (a reflectance peak at $\mathbf{r}=\mathbf{r}^{\prime}$ ). The width of this peak is related to the shape and size of canopy elements, thus the hot spot parameter is representative of the ratio of leaf (or stem) size to canopy height and varies from 0 to 1 [Kuusk, 1991].

The most common method of inverting a radiative transfer model is to use an iterative optimization procedure that attempts to find the global minimum of a least-squares measure of error, the merit function:

$$
E^{2}(\mathbf{P})=\sum_{l} \sum_{l} w_{l} \cdot\left[R^{*}\left(\Theta_{1}, \lambda_{l}\right)-R_{\mathbf{P}}\left(\Theta_{1}, \lambda_{l}\right)\right]^{2},
$$

where $E^{2}$ is the sum-squared error, $\Theta_{i}=\left(\theta_{i}, \theta^{\prime}, \psi_{i}\right)$ represents the set of sun-sensor geometries $\left(r_{1}, \mathbf{r}^{\prime}\right), \mathbf{R}^{\prime \prime}$ is the measured reflectance, and the summation is over the total number of measurements at hand: the unique geometrical configurations $(i=1, \ldots, N)$ times the number of spectral bands per measurement. Goel and Thompson [1984] have shown that the SAIL model is mathematically invertable in this manner. In the case of AVHRR, $j$ is either 1 (visible) or 2 (near-infrared). In addition, a set of weighting coefficients $w_{y}$ may be applied to reflect the relative importance of directions and wavelengths with respect to the slope of the merit function [Privette et al., 1996] and thus improve the convergence of the optimization. We have left all $w_{y}=1$ in this study, but are planning to investigate the usefulness of nonunit weights. Equation (2) assumes that there is a

Table 1. The SAIL-2 Model Parameters and their Bounds or Default Values for three Inversion Experiments

\begin{tabular}{|c|c|c|c|c|c|c|c|}
\hline \multirow[b]{2}{*}{$\mathrm{i}$} & \multirow[b]{2}{*}{ Parameter $\left(P_{1}\right)$} & \multicolumn{2}{|c|}{ Configuration Gl } & \multicolumn{2}{|c|}{ Configuration $\mathrm{G} 2$} & \multicolumn{2}{|c|}{ Configuration $\mathrm{F}$} \\
\hline & & Mode & Value & Mode & Value & Mode & Value \\
\hline 1 & Plant area index & free & $05-10.0$ & free & $0.5-10.0$ & free & $05-10.0$ \\
\hline 2 & Stem fraction & free & $00-0.5$ & free & $0.5-1.0$ & free & $01-0.9$ \\
\hline 3 & Leaf red reflectance & range & $005-0.17$ & free & $0.05-0.17$ & free & $0.05-0.17$ \\
\hline 4 & Leaf NIR reflectance & linked & $f\left(\mathrm{P}_{3}\right)$ & linked & $f\left(\mathbf{P}_{3}\right)$ & linked & $f\left(\mathrm{P}_{3}\right)$ \\
\hline 5 & Leaf Red transmittance & lınked & $f\left(\mathrm{P}_{3}\right)$ & linked & $f\left(\mathrm{P}_{3}\right)$ & linked & $f\left(\mathrm{P}_{3}\right)$ \\
\hline 6 & Leaf NIR transmittance & linked & $f\left(\mathrm{P}_{3}\right)$ & linked & $f\left(\mathrm{P}_{3}\right)$ & linked & $f\left(\mathrm{P}_{3}\right)$ \\
\hline 7 & Stem red reflectance & free & $0.1-04$ & range & $0.1-0.4$ & range & $01-04$ \\
\hline 8 & Stem NIR reflectance & linked & $f\left(\mathrm{P}_{7}\right)$ & linked & $f\left(\mathbf{P}_{7}\right)$ & linked & $f\left(\mathrm{P}_{7}\right)$ \\
\hline 9 & Mean leaf angle & linked & $f\left(\mathrm{P}_{7}\right)$ & linked & $f\left(\mathrm{P}_{7}\right)$ & fixed & 0.0 \\
\hline 10 & Stem NIR transmittance & linked & $f\left(\mathrm{P}_{7}\right)$ & linked & $f\left(\mathrm{P}_{7}\right)$ & fixed & 0.0 \\
\hline 11 & Mean leaf angle & fixed & $50^{\circ}$ & fixed & $50^{\circ}$ & fixed & $50^{\circ}$ \\
\hline 12 & Mean stem angle & fixed & $50^{\circ}$ & fixed & $50^{\circ}$ & fixed & $60^{\circ}$ \\
\hline 13 & Leaf hot spot parameter & fixed & 0.4 & fixed & 0.4 & fixed & 0.1 \\
\hline 14 & Stem hot spot paramter & fixed & 04 & fixed & 0.4 & fixed & 0.5 \\
\hline 15 & Soil red reflectance & range & $0.06-04$ & range & $006-04$ & range & $006-0.4$ \\
\hline 16 & Soil NIR reflectance & linked & $f\left(\mathrm{P}_{15}\right)$ & linked & $f\left(\mathrm{P}_{15}\right)$ & linked & $f\left(\mathrm{P}_{15}\right)$ \\
\hline 17 & Horizontal visibility & fixed & $50 \mathrm{~km}$ & fixed & $50 \mathrm{~km}$ & fixed & $50 \mathrm{~km}$ \\
\hline 18 & Cover fraction & range & $0.5-0.8$ & range & $08-10$ & fixed & 099 \\
\hline
\end{tabular}

The mode indicates how each parameter was treated in the inversion process: 'free' means optimization was performed to retrieve these parameters, 'fixed' means these parameters were specified prior to inversion and held constant, 'range' means these parameters were fixed for each optimization in an ensemble, and 'linked' mean these parameters were determined as a function of some other parameter (based on field data). 
multiple sampling of geometry, which is not strictly possible with AVHRR for a single target and satellite overpass, but we present one method for approximating this sampling in the next section.

Given that the principal independent variables are $\Theta$ and $\lambda$, the shape of the BRF with respect to the sun-sensor orientation and to wavelength is the fundamental profile used to characterize the land surface. A basic fact of remote sensing is that in order to retrieve some quantity $P_{1}$, the BRF must be sensitive to small changes in that parameter, illustrated by

$$
\frac{d R(\Theta, \lambda ; \mathbf{P})}{d P_{l}}>\varepsilon
$$

where $\varepsilon$ represents some measure of the noise threshold in the data. As an example, reflectance in both the red and NIR bands saturates with increasing LAI. This implies (as mentioned in the Introduction) that the derivative in (3) approaches zero, and thus it is increasingly difficult to determine LAI at high values of LAI. An additional directional measurement (i.e., incremental sampling of $\Theta$ ) is useful for determining $\mathbf{P}$ when the derivative with respect to some parameter $P_{l}$ at the new measurement geometry $\Theta^{\prime}$ is not equal to the derivative at another available $\Theta_{r}$. The measurement is then said to be independent and it contains new information. The number of independent measurements needed depends on the quality of model and data, the nature of the target, and the desired number of retrieved parameters.

If there are $M$ parameters and $2 N$ measurements, and if one attempts to retrieve $m<M$ free parameters, then an obvious requirement is that $2 N \geq m$. However, due to the existence of noise in the data and inaccuracy in the model it is desirable to have $N$ as large as possible and $m$ as small as possible. Because reducing the number of free parameters $m$ in the inversion increases the likelihood of a successful optimization (retrieval), those with less sensitivity can be held fixed at little cost to accuracy. In addition, if functional relationships can be found between parameters, it will reduce the dimensionality of the parameter space. Finally, it may also be useful to apply an ensemble of fixed parameters and average the results. All of these techniques have been used in this study.

When an acceptable parameter set $\mathbf{P}$ of the RT model has been recovered from the data (i.e., a minimum of $E^{2}(\mathbf{P})$ has been found), daily total fAPAR (П) [e.g., Goward and Huemmrich, 1992] is obtained by diurnal integration:

$$
\Pi=\frac{\int_{1} d t\left[\cos \left(\theta^{\prime}(t)\right) \cdot f_{\mathrm{P}}\left(\mathbf{r}^{\prime}(t), \lambda_{\pi}\right) \cdot E_{\mathrm{s}}\left(\lambda_{\pi}\right)\right]}{\int_{7} d t\left[\cos \left(\theta^{\prime}(t)\right) E_{\mathrm{i}}\left(\lambda_{\pi}\right)\right]},
$$

where $T$ is the number of daylight hours (dependent on latitude and time of year), $\lambda_{\pi}$ is the photosynthetrcally active radiation (PAR) portion of the spectrum, and $f_{\mathrm{P}}$ is the instantaneous PAR absorbed by the canopy. Albedo $(\alpha)$ is computed by hemispheric integration [Ross, 1981]:

$$
\alpha=\frac{\int_{\Lambda} d \lambda \int_{\omega_{1}} d \Omega \int_{\omega_{1}} d \Omega^{\prime}\left[\cos (\theta) \cdot \cos \left(\theta^{\prime}\right) \cdot R_{\mathbf{P}}\left(\mathbf{r}, \mathbf{r}^{\prime}, \lambda\right) E_{,}(\lambda)\right]}{\int_{\Lambda} d \lambda \int_{\omega_{1}} d \Omega^{\prime}\left[\cos \left(\theta^{\prime}\right) \cdot R_{\mathbf{P}}\left(\mathbf{r}, \mathbf{r}^{\prime}, \lambda\right) \cdot E_{\varsigma}(\lambda)\right]}
$$

where $\Lambda$ is the entire solar spectrum $(-0.03-1.2 \mu \mathrm{m})$ and $\omega_{1}$ is the upper hemisphere.

\section{Methods}

The basis of our approach is the simulation of a geometrical sampling of the BRF by aggregating the reflectance data unto cells that contain many individual $8-\mathrm{km}$ pixels, retaining the associated location-specıfic values of reflectance, sun-sensor geometry, and quality control indicators. Because of the Pathfinder compositing, spatially adjacent pixels are often obtained with significantly different sunsensor angles. Thus, withın regions and 10-day composites, significant angular information exists, although each pixel is at a single angle. We reasoned that most relatively undisturbed systems, which are heterogeneous at sub-kilometer scales, may represent reasonably homogeneous mixtures at $1-\mathrm{km}$ scales and larger, and that pixels withın a region may each contann consistent mixtures of the same types (e.g., $x \%$ trees, $y \%$ shrubs, and $z \%$ grasses). Thus, multiple pixels within some grid cell could be used to produce a synthetic BRF for that grid cell, simulating multiple measurements of a (cell-sized) target.

\section{Stratification of the Continental-Scale Data Using a Vegetation Index}

We chose a region in central Africa for initial testing. The region was chosen because it contans extensive continuous mixtures of natural vegetation and because it is the site of an ongoing interdisciplinary investigation. The first step was to perform a series of large-scale analyses with AVHRR data using a vegetation index in order to assess: (1) the appropriate cell size and shape, and (2) a basis for excluding pixels from a cell that are outliers. We took NDVI from the Pathfinder data for the African continent and created a VI climatology by recompositing to maximum monthly NDVI, cloud and QC filtering (rejecting questionable observations), then averaging over the 3 years for each month, that is,

$$
\overline{\mathrm{NDVl}}_{l}=\frac{1}{3}\left[\sum_{l} \mathrm{filt}\left(\max \left(\mathrm{NDVI}_{l}\right)\right)\right]
$$

where $\iota=(\mathrm{Jan}, \ldots, \mathrm{Dec})$ and $\jmath=(1986, \ldots, 1988)$. We then performed a principal components (PC) rotation on the $\overline{\mathrm{NDVI}}$ to define a set of new, orthogonal variables. The first three PCs explain $96 \%$ of the total variance. As the principal components of a stationary time series are equivalent to Fourier components, the first three PCs roughly correspond to the mean greenness, and the amplitude and phase of the seasonal cycle. Higher-order components are significant only for some isolated areas, amounting to a very small percentage of all pixels in Africa. The images in Plate $2 a$, and $2 b$ show the first three PCs as a mixture of red(1), green(2), and blue(3). Functional ecotypes can be identified as having approximately the same color; this mapping may be thought of as a continuous, unlabeled vegetation characterization. A discrete characterization can also be obtained by clustering the PCs into a number of unique, idealized classes. Similar multi-temporal characterizations of spatial data have been presented in the literature [Andres et al., 1994, Running et al., 1995]. 


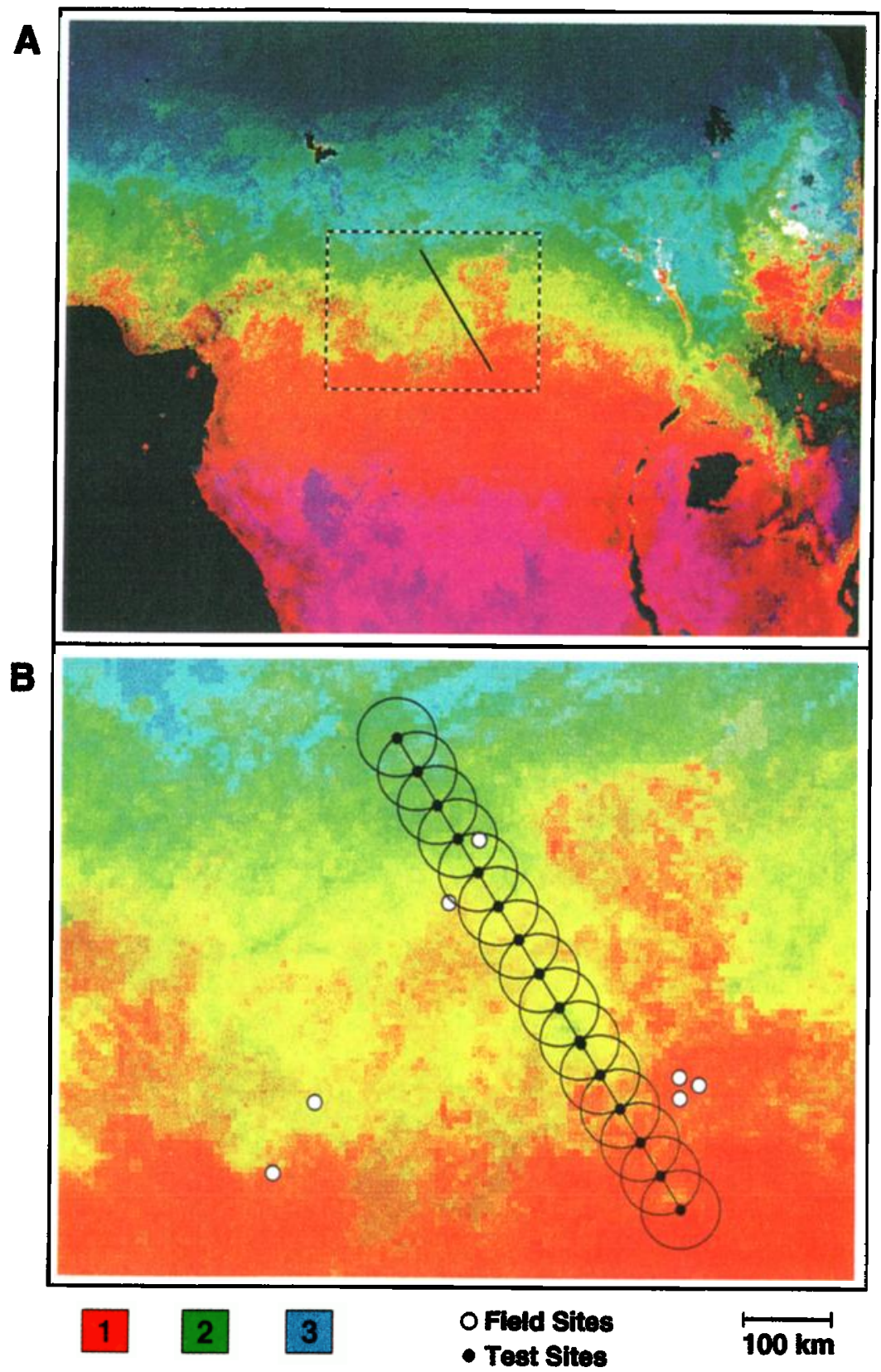

Plate 2. Phenological characterization of Africa. (a) Principal components 1,2 , and 3 as a mixture of red, green, and blue. Inset is $2 b$, showing the transect line. (b) The transect of 15 "cells" from grassland (blue pixels) to evergreen forest (orange pixels). Also shown are field sites where soil/litter reflectance was measured.

We initially classified African vegetation using the first three PCs of the $\overline{N D V I}$ into forest, savanna and grassland, and desert, using the K-means method [Spath, 1980]. We then computed the semivariance of the $\overline{N D V I}$ in the N-S and $\mathrm{E}-\mathrm{W}$ directions within types, focusing on the directional semivariance because of the strong anisotropy of vegetation density (at the continental scale) in Africa. Sills for the semivariance were typically higher E-W than N-S because of the influence of the strong $\mathrm{N}-\mathrm{S}$ precipitation gradient in the Sahel. We set as a maximum threshold for grid cell radius the scale length (typically less than $200 \mathrm{~km}$ ) of the E-W semivariance, and we set as a minimum the grid cell size sufficient to obtain an adequate sampling of the BRF as determined by the number of unique geometri- cal configurations. Empirical evaluation of these joint constraints for this region resulted in grid cell sizes of $50-\mathrm{km}$ radius. At this resolution, the spatial continuity is approximately isotropic, so the choice of circular grid cells is appropriate. Plate $2 b$ shows the transect of overlapping grid cells used in this analysis. For future reference, we adopted the convention of numbering the cells from 1 to 15 starting at the northernmost cell. The discrete classification (for the entire continent) mentioned above resulted in this transect being broken into two classes, with the between-class line falling very close to cell 11 . We thus refer to cells 1-10 as being a savanna/grassland mosaic, cells $12-15$ as being evergreen/deciduous forest, and cell 11 as "transitional". 
A

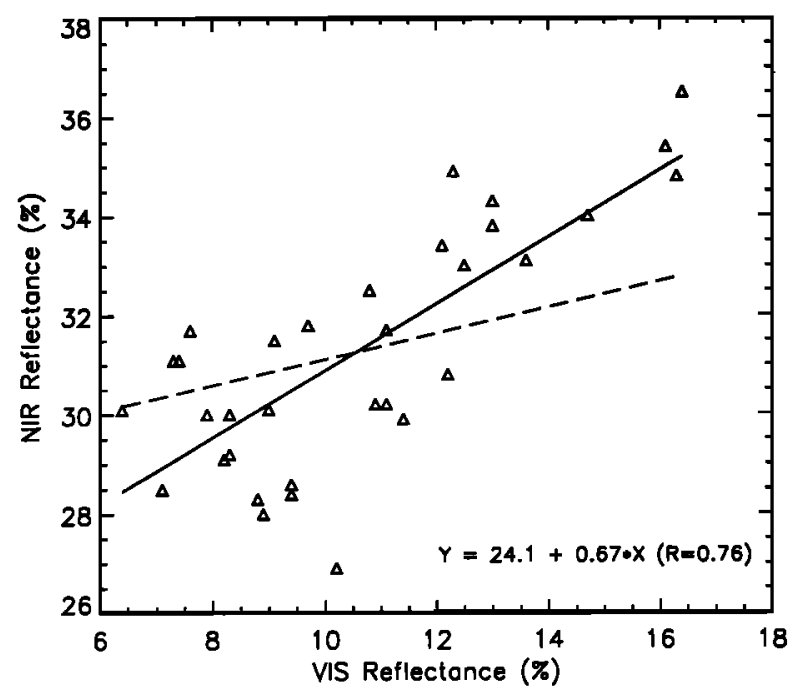

C

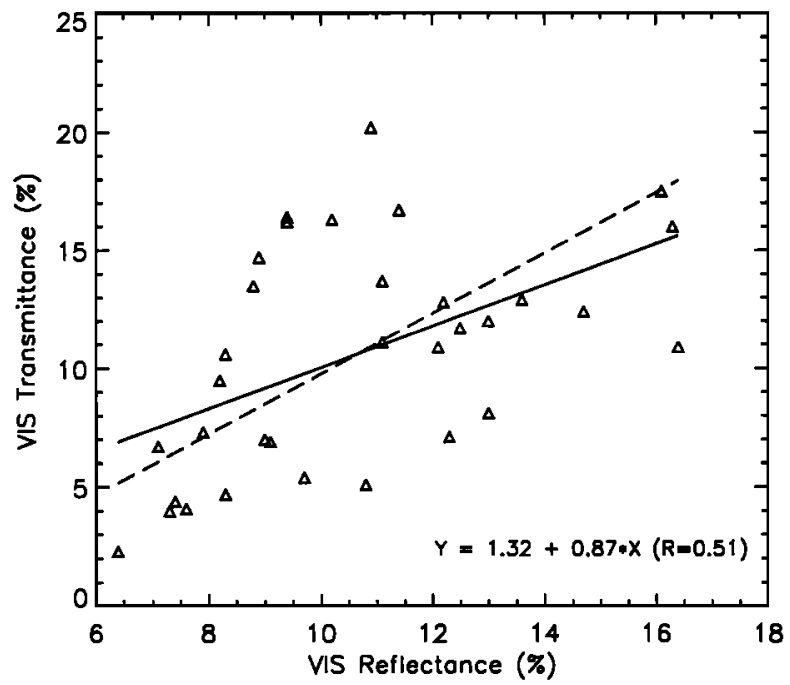

B
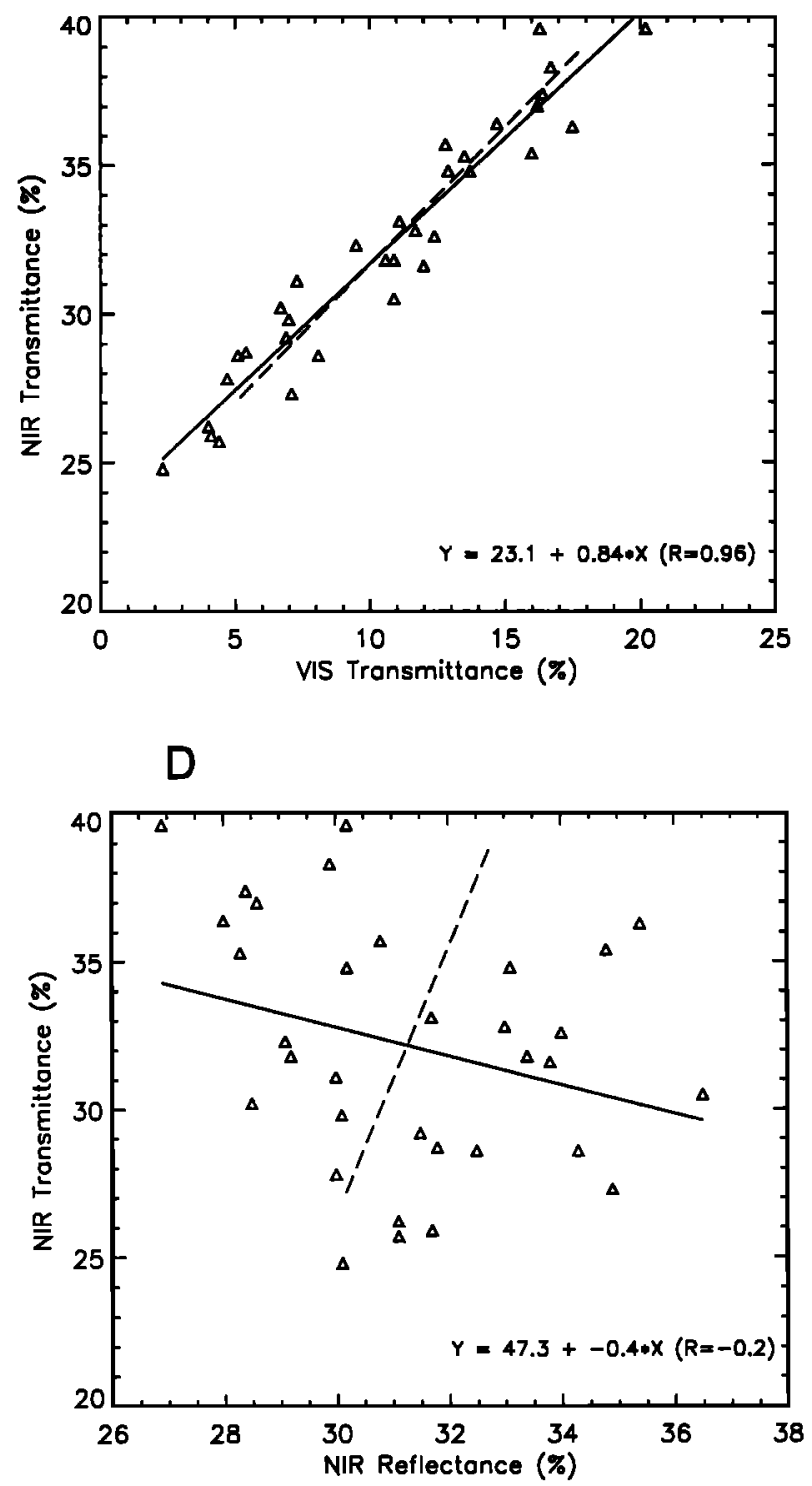

Figure 1. Leaf reflectance and transmittance data, convolved to the four leaf optical variables used in SAIL2 and plotted against one another. The solid line is the line of best fit, and the dashed line is the relationship obtained by writing all four variables in terms of the first PC of the leaf data.

\section{Leaf and Soil Optical Measurements}

It is useful to obtain relationships between model parameters in order to reduce the number of free parameters in the inversion. This can be accomplished by specifying a functional relationship between a variable and another (independent) variable, thus each time that variable is referenced during the optimization, it is assigned a value according to the prescribed function. We identified the leaf and soil/background optics variables as being most appropriate for data reduction because of the typically strong autocorrelation in their reflectance/transmittance spectra.

An integrating sphere was used to measure the leaf optical properties of a set of savanna plants that were grown in a greenhouse. The leaves were of varying age and morphology. The measured reflectance and transmittance spectra were convolved with the AVHRR sensor bandwidths and the solar spectrum to produce visible (channel 1) and
NIR (channel 2) values for reflectance and transmittance. Each point on Figures 1a-1d represents one of these reduced-spectral measurements. We wished to represent the four leaf optical parameters with a single variable, but this cannot be accomplished using the pairwise lines of best fit (solid lines in Figure 1). Principal components analysis yielded a $60 \%$ explanation of total variance by the first PC. Thus, we used the first PC of these data to express visible leaf transmittance and NIR leaf reflectance and transmittance as a linear function of visible leaf reflectance. The resulting relationships are shown as dashed lines in Figure 1 and represent the best way (in the least squares sense) to represent all the leaf optical parameters with one free variable.

The same spectral averaging technique was used for soil/litter reflectance. In January-February, 1995, we (coauthors EWS and ATH) visited a series of sites in the Cen- 


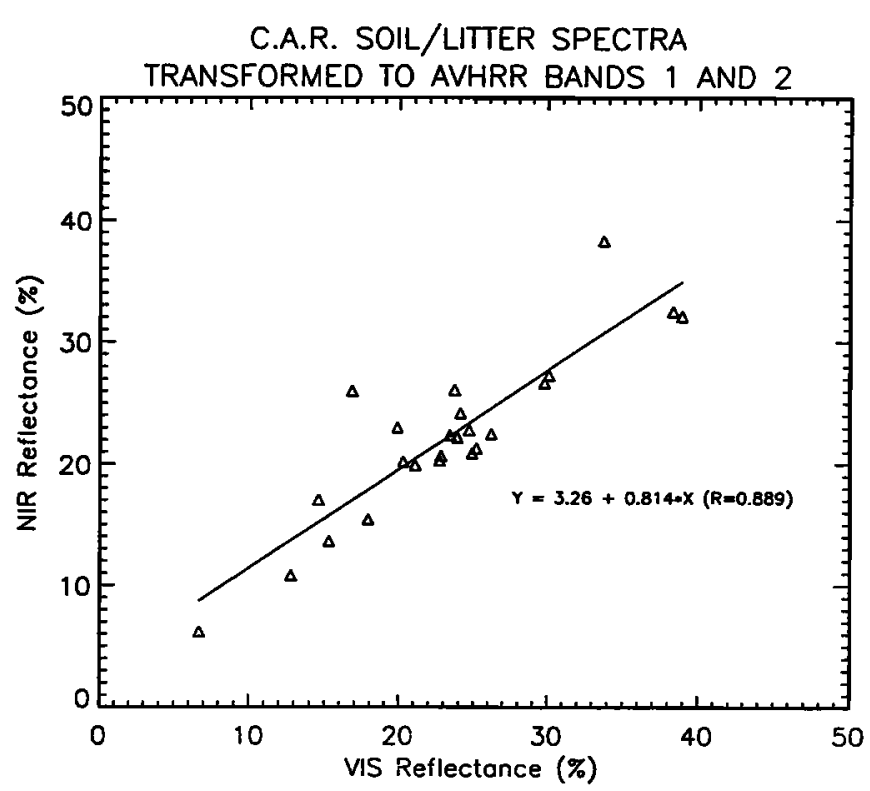

Figure 2. Similar to Figure 1 except for field measured soil spectra. The line of best fit was used in the inversion.

tral African Republic (C.A.R.) spanning the forestsavanna-grassland transition (Plate $1 \mathrm{~b}$ ). LAI and soil/litter reflectance were measured at each site, including background spectra from areas that were recently burned. Wet soil reflectance was also measured at each site. The combined soil and litter reflectance data were transformed into AVHRR-equivalent values using the same convolution method as for leaves. Using the transformed data, we developed a relationship between soil reflectance in the visible and NIR wavelength regions (Figure 2). The soil line function, together with the leaf optics function, effectively reduce six of the model parameters (four for leaves, two for soil) down to two model parameters.

\section{Inversion Methodology}

We then extracted synthetic BRFs from a transect of grid cells in the C.A.R. (Plate $2 a$ and $2 b$ ) for all months of 1986. The transect is $800 \mathrm{~km}$ long and consists of 15 cells; each cell is approximately $50 \mathrm{~km}$ in radius and consists of 121 Pathfinder $(8 \times 8 \mathrm{~km})$ pixels. This focused study region represents an ecological gradient from grassland in the north to evergreen tropical forest in the south, with mixtures of grassland, savanna, and woodland in between.

Multiple, geometrically unique observations of a target are required in order to use the bidirectional information to retrieve parameters, so this technique has operational value only if each cell contains pixels with significantly different sun-sensor geometry, and if the degree of sampling is consistent over time. This is true for the cells on our transect, as demonstrated in Plate 3a for cell number 1. Sun-sensor phase angle is a proxy for the full geometrical configuration (Plate 3b shows the September geometries), so we

A

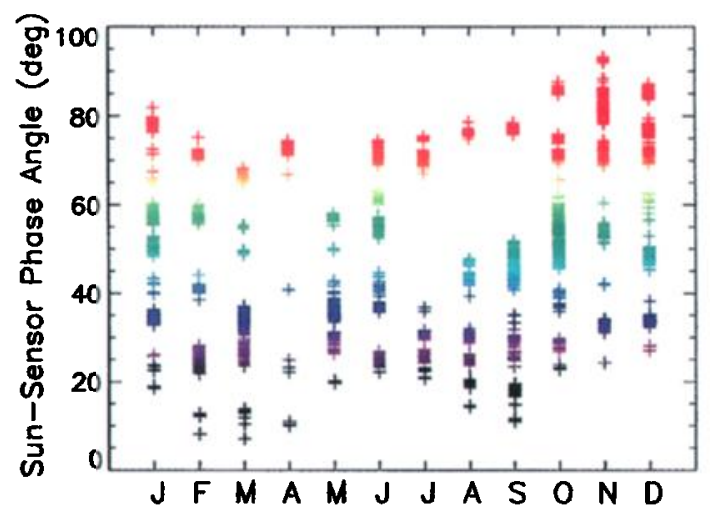

B

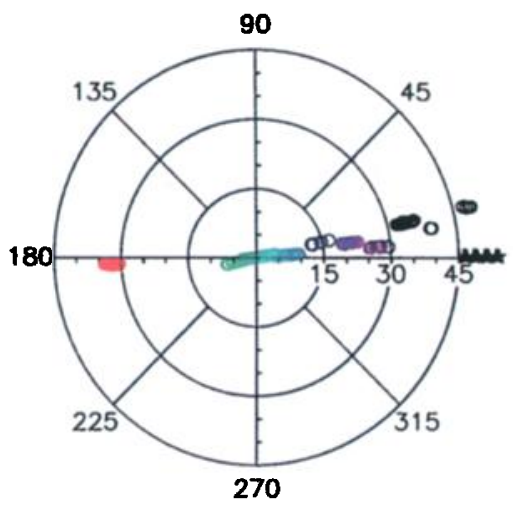

C

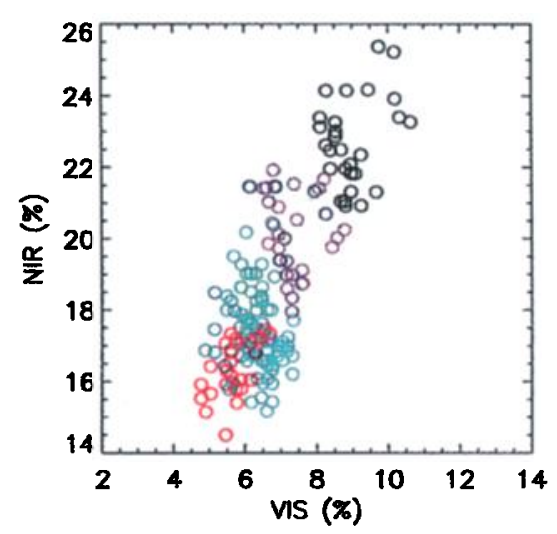

D

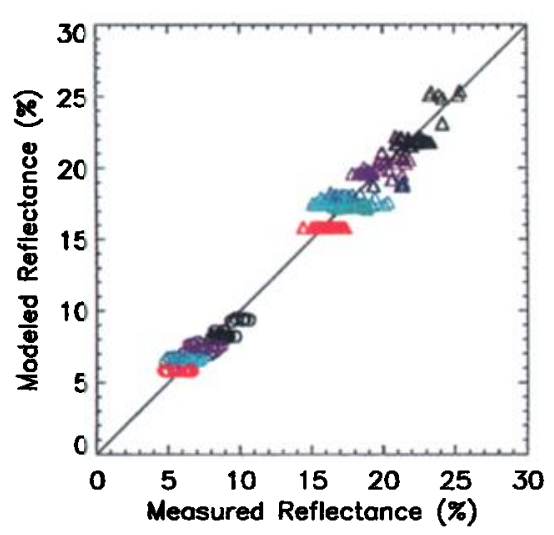

Plate 3. (a) Sun-sensor phase angle for a typical site as a function of time. (b) The full sun-sensor geometry for September. (c) Measured visible and NIR reflectances for the same data as in $3 b$. (d) Measured versus modeled reflectance after inversion on the data from $3 b$ and $3 c$. 


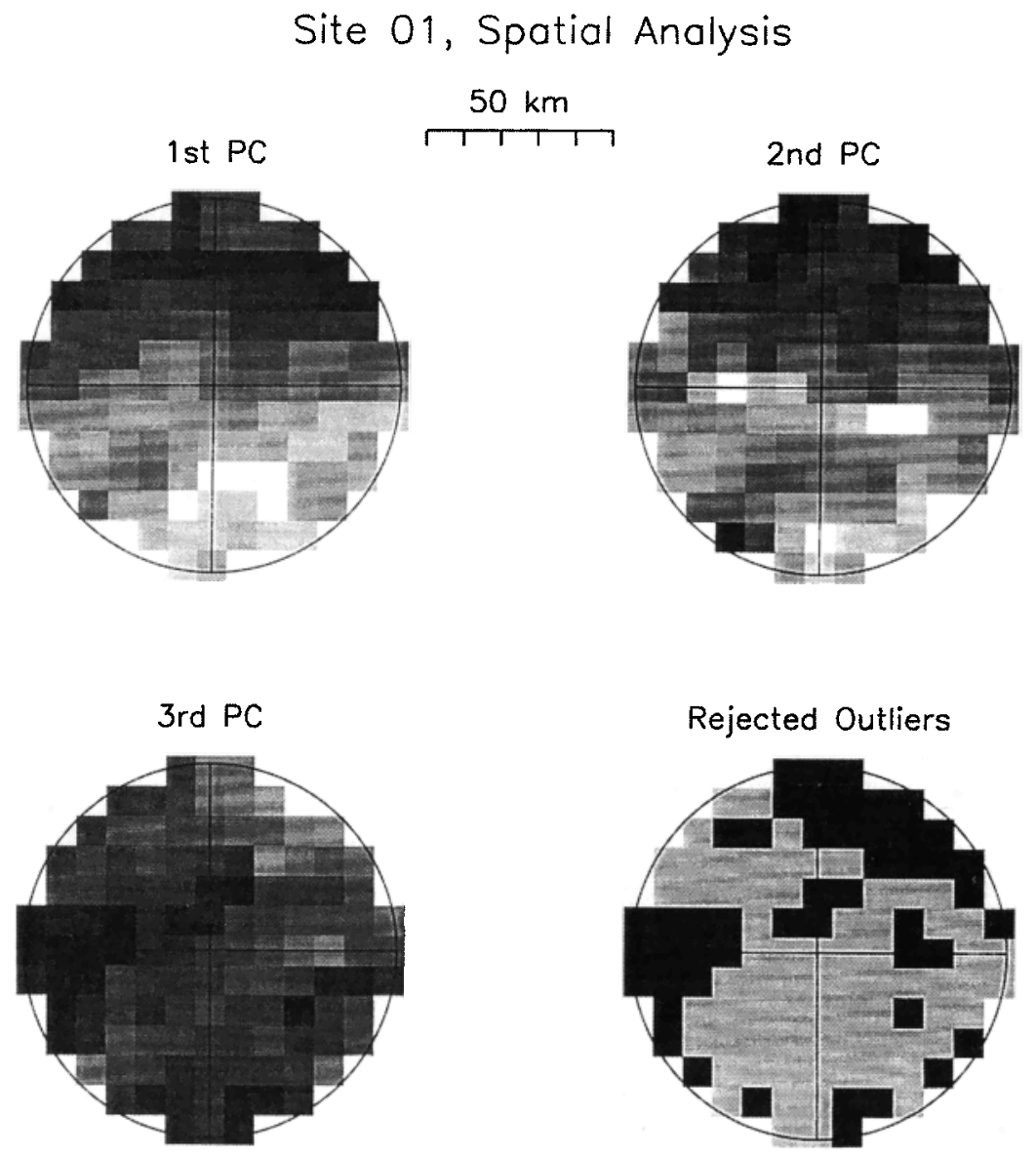

Figure 3. A typical cell characterized by a PC analysis of multitemporal normalized difference vegetation index (NDVI) data. Individual pixels are rejected if they differ from the modal cell value for any PC by more than $10 \%$ of the continental range of values for that PC.

have color-coded all points in Plate $3 a-3 d$ by the phase angle.Plate $3 c$ is the realization of an actual BRF distribution; pixels with similar geometry have similar reflectance values. In fact, this is a fairly typical profile, showing high backscatter reflectance, and lower reflectance in the forward scatter directions and at nadir.

Outlier pixels within grid cells were rejected on the basis of a similarity criterion, following the PC characterization of Africa. This effectively excluded lakes, villages, some river corridors, and vegetated areas that differ greatly from the dominant local structural-phenological type. The first three PCs of the $\overline{\mathrm{NDVI}}$ data were used to apply a consistent requirement of similarity to each cell. Any pixel that differed from the modal $\mathrm{PC}$, value (for $i=1,2,3$ ) by more that $10 \%$ of the total range of $\mathrm{PC}_{i}$ values for Africa was excluded. No more than half of the pixels were excluded from any given cell. On average, $70 \%$ of pixels were retained. Figure 3 shows the PC1-PC3 values and the rejected pixels for a typical cell (number 1 ).

A number of free parameter retrievals were performed on the transect of AVHRR data for 1986. We used three fixed parameter sets, shown in Table 1 as G1, G2, and F. Parameters in each configuration could be free and bounded, fixed at different values in an ensemble, constant, or functionally linked to another variable. The three configurations in this experiment correspond to an idealized grassland in the dry season (G1; more dead grass than live grass), a grassland in the wet season (G2; mostly green grass), and an ideal forest (F). For the grassland sets, stems were assumed to be senescent leaves and thus the relationship between NPV optical variables is the same as for leaves. Also, having the same shape as green leaves, they are assigned the same leaf hot spot parameter. The main difference between $\mathrm{G} 1$ and $\mathrm{G} 2$ is that the optical properties of NPV are free in the G1 inversion, and fixed in the G2 inversion (Table 1). This is because the relative abundance of NPV versus active leaves dictates, in part, the sensitivity of the optical parameters (see equation 3 ). In the forest set, stems are assumed to be tall (large hot spot effect) and the green leaves small with respect to canopy height. Tree stems are also assumed to have zero transmittance.

For all the retrievals we inverted the SAIL-2 model on three free parameters: plant area index, stem fraction, and component (leaf/stem) reflectance in the visible. We used the optimization routine E04JAF (a quasi-Newton algorithm with simple bounds) from the Numerical Algorithm Group , to perform the inversions. Nearly all attempts at inverting with four free parameters failed, as did attempts where one of the three parameters above was fixed and any other parameter (e.g., soil reflectance) was free. By failure we mean that the optimization routine could not find a minimum of the merit function (equation 2) given the pa- 
rameter defaults and constraints (Table 1 ). It is a convenient and important fact that when a parameter set is too unrealistic to allow a solution within the bounds provided, the inversion returns with a null result. Our subsequent inference that the three "key" parameters above have the greatest BRF sensitivity (equation 3 ) over the range of canopy conditions encountered in this study is consistent with the analysis of Privette [1994].

A successful inversion, by definition, yields reflectances that agree as closely as possible with the measured AVHRR reflectance values. Plate $3 d$ shows a typical (described above) set of modeled versus measured reflectances, corresponding to $R_{\mathrm{p}}$ and $R^{*}$ in (2). The two clumps correspond to channel 1 (circles) and channel 2 (triangles). The $1: 1$ relationship in this figure is indicative of the success of the optimization, and the scatter reflects the magnitude of the merit function $E^{2}$ in (2). The plot of $R_{\mathrm{P}}$ versus $R^{*}$ (Plate $3 \mathrm{~d}$ )

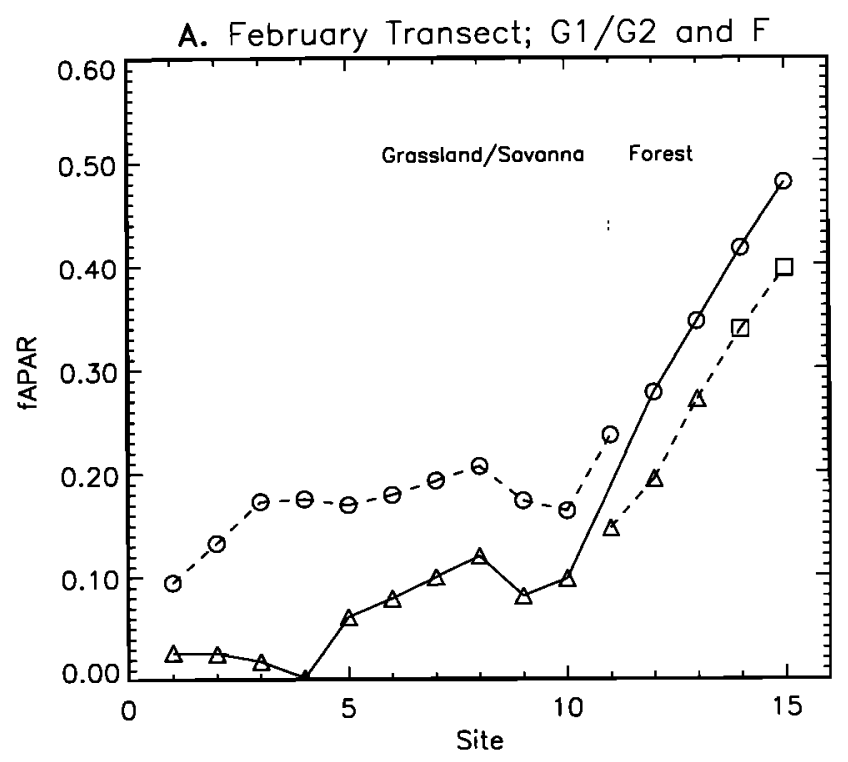

C. Site 1 Time Series; G1/G2

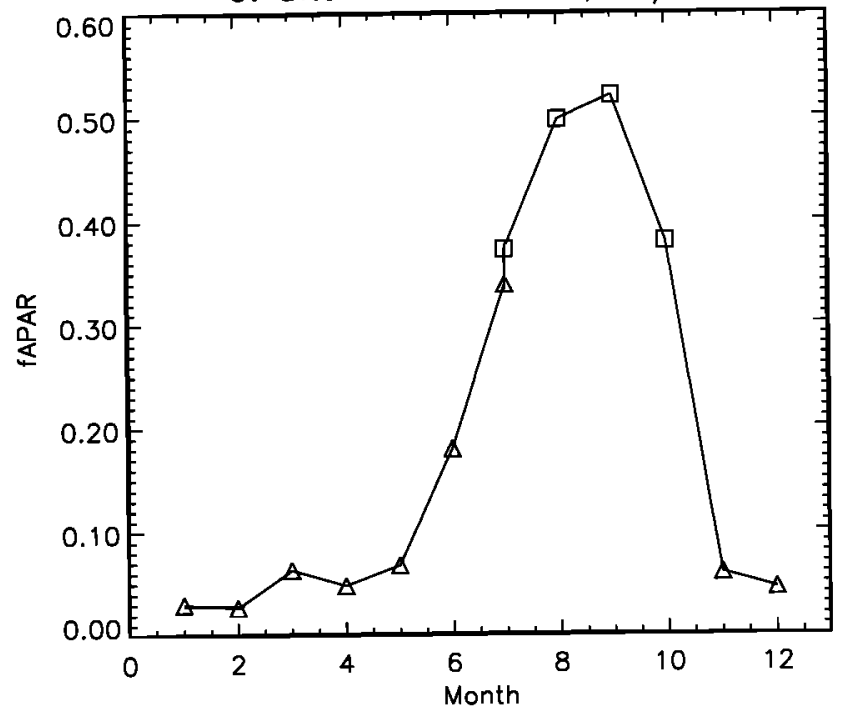

indicates that the inversion has succeeded, and that the relationship between measured and modeled reflectances are well-behaved with respect to geometry.

\section{Results}

The SAIL-2 model was inverted on the harvested AVHRR data to obtain $\mathbf{P}$ for each cell and for each month of 1986, using parameter configurations G1, G2, and F (Table 1). Given the retrieved canopy structural and optical parameters, forward integrations (equations 4 and 5) yielded daily total fAPAR [Goward and Huemmrich, 1992] and broad band albedo. These secondary products are assumed to be more robust than the elements of $\mathbf{P}$ (e.g., LAI) because they integrate all of the model canopy properties and because they are radiative quantities. Our field measured LAI (sites shown in Plate 2b) data are not directly

\section{B. September Transect; G2 and F}

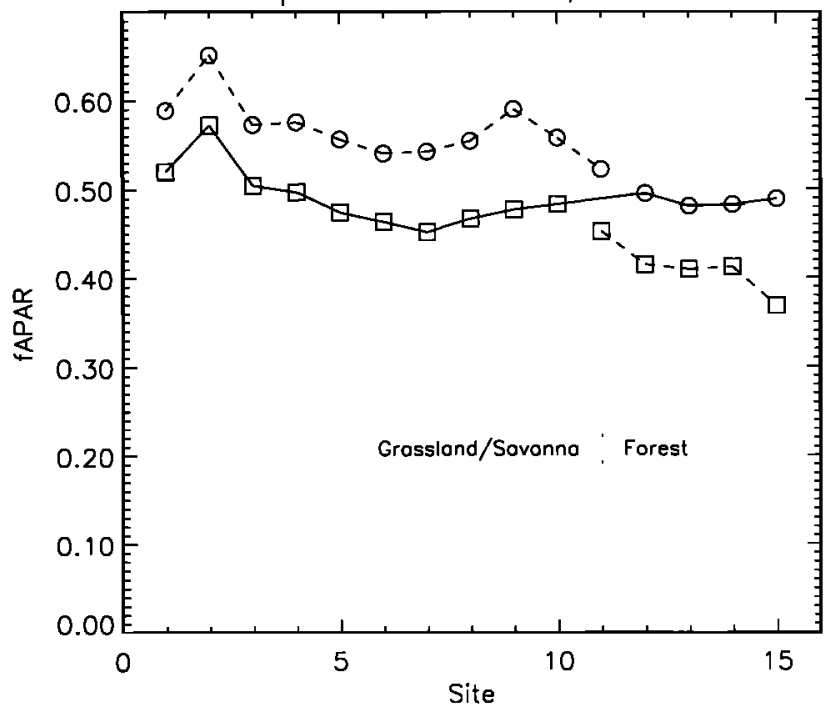

D. Site 14 Time Series; F

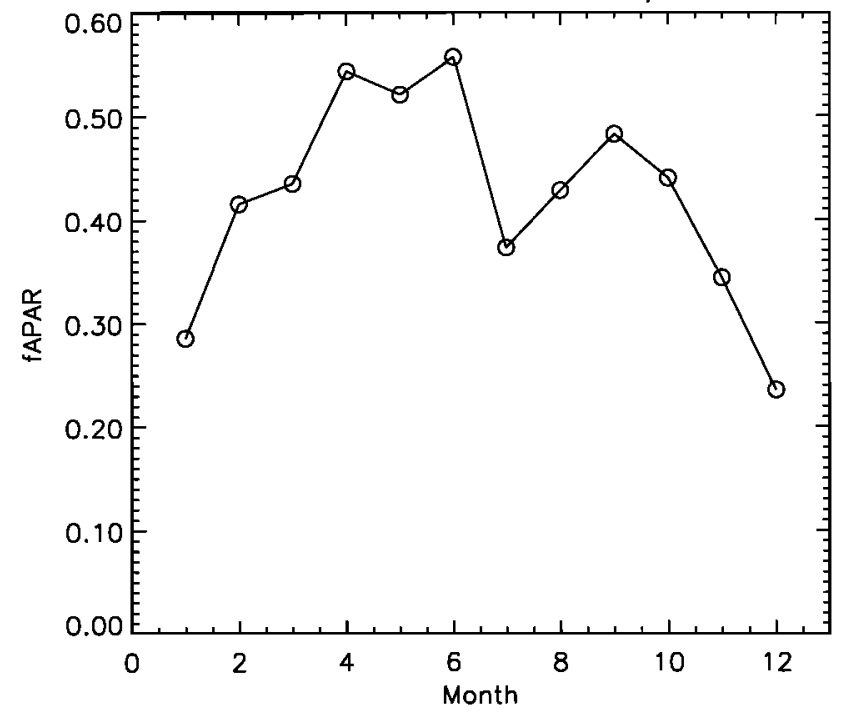

Figure 4. (a) Retrieved fAPAR along the transect in the dry season (February). The solid line connects the points with parameterizations that are appropriate for the vegetation type. G1, triangles; G2, squares; F, circles (see text). (b) The same as 4a except for September. (c) An fAPAR time series for the northernmost cell (1), using the G1 and G2 parameterizations. (d) The same as 4c except for the southernmost cell (15). 


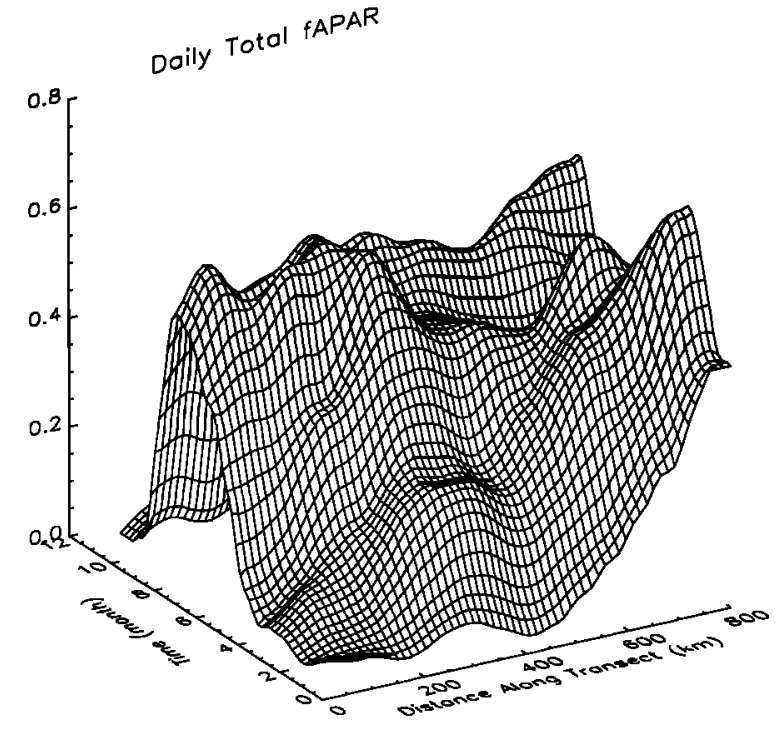

Figure 5. Retrieved fAPAR values along the transect as a function of time.

comparable to the SAIL-2 retrievals of LAI $\left(P_{1} \cdot\left(1-P_{3}\right)\right)$, primarily because of the 9 -year time difference, but they can provide a check on the results. In Jan. 1995, forest site LAIs were observed, ranging from $5.5 \pm 0.6$ in the evergreen tropical forests to $3.0 \pm 0.4$ in disturbed, upland sites. By comparison, retrieved forest LAI ranged from $4.6 \pm 2.0$ (cell 11) to $2.8 \pm 0.5$ (cell 14 ).

We merged the fAPAR results for the three parameter configurations (G1, G2, and F) using the classification discussed above. The "grassland" parameterizations G1 and G2 were assumed to represent cells 1-10, results for cells 12-15 were taken from the "forest" $F$ inversions, and cell 11 was assigned the mean of the G1/G2 and $F$ results (Figure $4 a-4 b)$. Figures $4 a$ and $4 c$ also demonstrate the important success/failure phenomenon of the inversion. An

A.

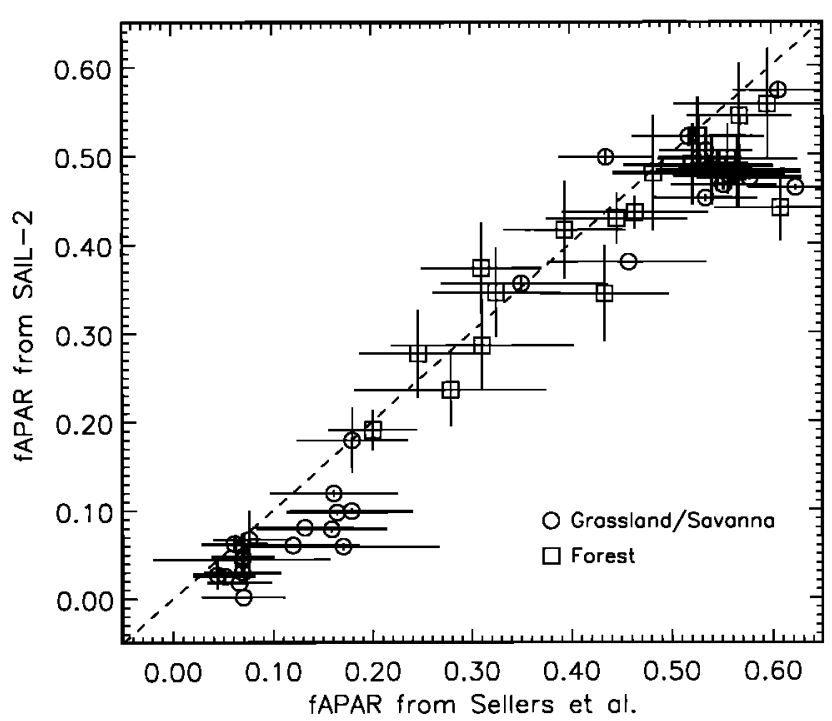

unrealistic parameterization does not generally allow for a solution, so the "dry grass" G1 inversions fail during the peak growing season months, and the "green grass" G2 inversions are successful only during this period. The merged fAPAR results for all sites for one year are shown in Figure 5. The spatial-temporal patterns of daily total fAPAR seen in Figures 4a-4d and in Figure 5 are a realistic depiction (based on field experience and accepted ecological knowledge) of the vegetation canopy dynamics in this region. The amplitude and timing of the seasonality decreases from north to south, producing a sharper N-S gradient in the dry season than in the wet season (consistent with the geostatistical description discussed above). A slight bimodal seasonality can also be seen at the southern points, in agreement with analyses of Olsson and Eklund [1994].

We compared our fAPAR results to those calculated using the VI-based method of Sellers et al. [1994] for the Simple Biosphere (SiB) model. There is roughly a $1: 1$ agreement (Figures 6a-6b) between the two approaches, but with a moderate amount of scatter $\left(R^{2}=0.88\right)$. Error bars for the Sellers et al. [1994] fAPAR result from within-cell variation of NDVI, while error bars on our estimates reflect the uncertainty propagated from the parameter ranges that were applied as part of an ensemble (Table 1). The forest NDVI were transformed into fAPAR using the equations for the SiB tropical evergreen class, and for the remaining cells, we used the SiB savanna equations (Figure 6a) and the $S_{1 B}$ grassland equations (Figure $6 \mathrm{~b}$ ). These figures show an offset between the SAIL-2 and the Sellers et al. [1994] determination of fAPAR, as well as a dependence on which VI transformation was used to get the savanna/grassland points. Also, the difference becomes amplified at high fAPAR values. The existence of a good relationship is possibly due to the fact that averaging VI values over a $50-\mathrm{km}$ radius cell reduces the effects of variable sun-sensor geometry and background reflectance. Less correspondence would likely be observed if data from a multi-angle like MISR [Diner et al., 1989] was used, be-
B.

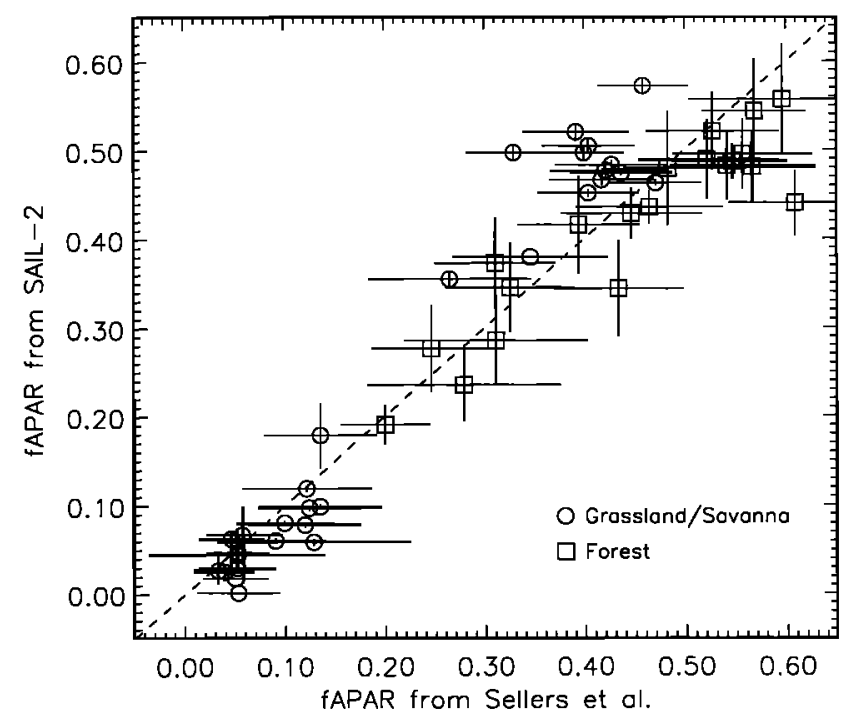

Figure 6. (a) A comparison of fAPAR derived from the SAIL-2 inversion and AAPAR using the vegetation index-based method of Sellers et al. [1994] for SiB forest (circles) and savanna (squares) types. (b) The same as $6 \mathrm{a}$ except using $\mathrm{SiB}$ forest (circles) and grassland (squares) types. 
Table 2. Broadband Albedo Estimates From the SAIL-2 Inversions Compared with the SiB Model and METEOSAT Data

\begin{tabular}{lccc}
\hline Location/Time & SAIL-2 & SiB $^{\mathrm{a}}$ & METEOSAT $^{\mathrm{b}}$ \\
\hline Cell 1, January (dry) & 0.10 & $0.15-0.20$ & 0.09 \\
Cell 1, September (wet) & 0.15 & $0.10-0.15$ & $0.16-0.18$ \\
Cell 15, January & 0.11 & $0.15-0.20$ & 0.10 \\
Cell 15, September & 0.12 & $0.10-0.15$ & $0.16-0.17$ \\
\hline
\end{tabular}

Cell 1 is centered at $8^{\circ} \mathrm{N}$, and cell 15 is centered at $4^{\circ} \mathrm{N}$.

${ }^{a}$ Dorman and Sellers [1989].

becker et al. [1988].

cause less spatial averaging would be required in the inversion.

Finally, we evaluated our estimated land surface albedo for the transect against the SiB model-derived estimates of Dorman and Sellers [1989] and an approximation using METEOSAT (a narrow-band visible weather monitoring instrument) data [Becker et al., 1988] along a transect at $20^{\circ} \mathrm{E}$. Table 2 shows the albedo comparison for both ends of the transect at two times of the year. Compared to SiB, our values are of comparable magnitude but they do not covary with respect to vegetation type and seasonality. However, the METEOSAT-derived albedo appears to show good agreement in magnitude and seasonality at both latitudes. An effort to compare our results to Earth Radiation Budget Experiment data is forthcoming and will provide more insight into the accuracy of these estimates.

The two comparisons with SiB formulations do not constitute validation of our inverse modeling results. At this time, VI-based algorithms are the only other way to estimate biophysical parameters at regional-to-global scales. The comparison demonstrates that our results (using unconventional methods) are comparable to other estimates, but it reveals some intriguing differences. Further, though it is likely that the fAPAR values derived from inverse modeling are more accurate than those using VI's because of their greater information content, the two techniques are suited for somewhat different applications. A VI-based approach is computationally fast, and more applicable for coarse resolution (e.g., GCM-scale) analyses. Inverse modeling applications are more computationally intensive, but are based on physical and ecological theory, and thus are more appropriate for detailed studies. Moreover, inverse modeling may feed back into the development of better VI algorithms, as is currently planned for the NASAEOS MODIS instrument [S. Running, personal communication, 1996].

\section{Discussion and Conclusions}

Satellite remote sensing allows for direct observation of the status of global vegetation at regular spatial and temporal intervals. This density of observation is important for monitoring terrestrial ecosystems because of the high spatial and temporal variability in climate forcing and because of the nonlinear response of terrestrial biugeulieininstiy, particularly factors relating to water and nutrient status. We have presented an algorithm for extraction of land surface biophysical information (LAI, fAPAR, and albedo) that is relevant for biogeochemical, ecological, and bio- physical modeling, and that has the following unique characteristics:

1. It uses real satellite data and a physically based model to retrieve parameters over large spatial areas. The SAIL-2 parameter set consists of measurable quantities (Table 1) and leads to estimates of $\operatorname{fAPAR}(\mathbf{x}, t)$ and albedo $(\mathbf{x}, t)$.

2. It simulates a multidirectional sampling of the BRF by gathering a spatial-temporal neighborhood of pixels with an assumed spatial continuity. This assumption is enforced by a principal components (or Fourier) decomposition analysis of a vegetation index climatology.

3. It allows for the incorporation of a priori ecological knowledge in the choice of parameter constraints and of the inversion mode (i.e., which parameters are held fixed, and which are free). This method highlights the importance of data describing soil and leaf optical properties keyed to global soils and vegetation databases. These data are readily but rarely measured.

4. It allows for direct incorporation of field measurements of plant canopy and surface soil/litter (background) characteristics, which typically reduce the number of free parameters in the inversion and may be applied over large areas, as in this study.

There are significant differences between our approach and VI-based, empirical approaches [Potter et al., 1993; Sellers et al., 1994; Ruimy et al., 1994]. First, we use both optical channels simultaneously instead of combining them into one index. Second, we retrieve parameters for a cluster of pixels (one cell) instead of for each pixel, effectively trading lower resolution for increased accuracy. Third, we explicitly account for the two factors that are most responsible for the distortion of the vegetation signal: background spectral variation and bidirectional effects. Fourth, we account for PAR interception by nonphotosynthetic vegetation which allows estimation of fAPAR for leaves. Finally, with inverse modeling, the uncertainty associated with lack of knowledge of some surface characteristics (parameters) and the validity of ecologically based assumptions may be quantified using fixed-parameter ensembles.

Our conclusion, based on these preliminary results, is that it is possible to retrieve land surface parameters from remotely sensed data using physical model inversions. Although we used a relatively simple RT model (SAIL), this method could easily be adapted to more sophisticated models [Privette et al., 1996]. However, more complex models generally have more parameters; thus they may not be advantageous unless (1) the remote sensing data contains more BRF information per unit area and less atmospheric noise (e.g., MISR), or (2) more ecological constraints are 
available. Because our method is based on physical modeling, it is probably more accurate than those achieved using VI-based algorithms (except those that are highly tuned), but this has yet to be established experimentally. Our method requires no empirical calibration between reflectance (or a VI) and any of the estimated variables: fAPAR, albedo, or LAI. Field validation is essential, but difficult, because of scaling issues associated with the estimation of LAI, albedo, or fAPAR over an area greater than or equal to $2500 \mathrm{~km}^{2}$. One way to attack the problem of verification is by using spectral unmixing techniques and data from other, higher-resolution sensors to bridge the gap between field measurements and continental-scale (e.g., AVHRR) data. These methods could also feed back to the large-scale parameter estimation by providing better quantification of canopy component properties. Indeed, the combination of inversion and unmixing techniques has been proposed as a "paradigm shift" in the remote sensing of vegetation biophysics [Hall et al., 1995].

Although the AVHRR Pathfinder data set is carefully processed, there are two "minor" problems with the first release of the data [Prince and Goward, 1996]: (1) the incident solar radiation was not adjusted for solar zenith angle; and (2) there was an error in the correction for atmospheric Rayleigh and ozone scattering. These translate into RMS reflectance errors for a typical composite of as much as $1-3 \%$ (M. James, official communication, 1995). Moreover, the data have not been corrected for the effects of scattering by atmospheric aerosols, which can be large. Further processing of Pathfinder data is currently being planned to correct these problems, which could lead to improved accuracy of our analysis. We feel that the successful inversions presented in this study using imperfect AVHRR data demonstrate the robustness of our algorithm.

This method can easily be used in the EOS framework, particularly with the MODIS and MISR sensors. Data from both sensors will be atmospherically corrected and calibrated with state-of-the-art techniques, and sampling rates of MODIS are comparable to those of AVHRR [Sellers and Schimel, 1993]. While MISR repeat samples are up to 9 days apart, that sensor's ability to measure a target at nine angles per satellite pass will likely result in smaller (and less heterogeneous) aggregation cells. Both sensors have spatial resolutions of less than 1 kilometer at nadir over several visible and NIR bands. The higher-resolution sampling of solar and PAR spectral wavelengths by MODIS should allow for better estimation of land surface properties such as fAPAR and albedo.

With algorithms such as the one presented in this paper, inversion methods will soon be mature enough for largescale applications. Automation of decisions that are based on geography, climate, time of year, etc. will be possible in conjunction with consideration of ecological factors. Because they are easily incorporated into inversion methods, improved understanding of ecosystems, radiative transfer, or optimization techniques as well as refinement of global ecological and soils databases will translate directly into a more accurate retrieval of biophysical parameters and may lead to a better understanding of the role of the terrestrial biosphere in the Earth system.

Acknowledgments. This work was supported by a fellowship appointment to the DOE Graduate Fellowships for Global Change, administered by the Oak Ridge Institute for Science and Education; and the National Aeronautics and Space Administration's Interdisciplinary Science Program (Schimel, Moore, and Dickinson IDS teams). We acknowledge the involvement of the FIRE team, from the Institute for Remote Sensing Applications, in the 1995 C.A.R. field campaign. The authors would like to thank Greg Asner and Becky McKeown for their typically helpful contributions. Stephane Jacquemoud and Andres Kuusk provided their implementation of A. Kuusk's hot spot parameterization. The National Center for Atmospheric Research is sponsored by the National Science Foundation.

\section{References}

Agbu, P.A., and M.E. James, The NOAA/NASA Pathfinder AVHRR land data set user's manual, Goddard Distributed Active Archive Center, NASA, Goddard Space Flight Center, Greenbelt, MD., 1995.

Andres, L., W.A. Salas, and D. Skole, Fourier analysis of multitemporal AVHRR data applied to a land cover classification, Int J Remote Sensing, 15, 1115-1121, 1994.

Asrar, G., M. Fuchs, E. T. Kanemasu, and J. H. Hatfield, Estimating absorbed photosynthetic radiation and leaf area index from spectral reflectance in wheat, Agronom. J., 76, 300-306, 1984.

Becker, F., H.-J. Bolle, and P.R. Rowntree, The International Satellite Land-Surface Climatology Project, ISLSCP Rep. 10, 100 pp., COSPAR, Int. Assoc. of Meteorol. and Atmos. Phys., Berlin, 1988.

Brown, O.W., J.W. Brown, and R.H Evans, Calibration of Advanced Very High Resolution Radiometer observations, J. Geophys. Res., 90, 11,667-11,677, 1985

Cihlar, J., D. Manak, and N. Voisin, AVHRR bidirectional effects and compositing, Remole Sensing Environ. 48, 77-88, 1994

Diner, D.J., et al., MISR: a multiangle imaging spectroradiometer for geophysical and climatological research from EOS, IEEE Trans Geoscl. Remote Sensing, 27, 200-211, 1989.

Dorman, J L., and P.J Sellers, A global climatology of albedo, roughness length, and stomatal resistance for atmospheric general circulation models as represented by the Simple Biosphere Model (SiB), J. Appl. Meteorol., 28, 833-855, 1989.

Goel, N.S., and R.L. Thompson, Inversion of vegetation canopy reflectance models for estimating agronomic variables, IV. Total inversion of the SAIL model, Remote Sensing Environ, 15, 237-253, 1984

Goward, S. N, and K. F. Huemmrich, Vegetation canopy PAR absorptance and the normalized difference vegetation index: An assessment using the SAIL model, Remote Sensing Environ. 39, 119-140, 1992.

Hall, F., Y.E. Shimabukuro, and K.F. Huemmrich, Remote sensing of forest biophysical structure using mixture decomposition and geometric reflectance models, Ecol. Appl., 5, 993-1013, 1995.

Holben, B.N., Characteristics of maximum-value composite images from temporal AVHRR data, Int. J. Remote Sensing, 7, 1417 $1434,1986$.

Huete, A., A soil adjusted vegetation index (SAVI). Remote Sensing Environ.. 25, 295-309, 1988.

Kidwell, K.B., NOAA Polar Orbiter Data User's Guide, NCDC/SDSD, National Climatic Data Center, Washington D.C., 1991.

Kuusk, A., The hot spot effect in plant canopy reflectance, PhotonVegetation Interactions, Applications in Optical Remote Sensing and Plant Ecology, edited by R.B. Myneni and J. Ross, pp. 9-44, Springer-Verlag, New York, 1991.

Myneni, R.B., G. Asrar, and F.G. Hall, A three dimensional radiative transfer model for optical remote sensing of vegetated land surfaces, Remole Sensing Environ, 41, 105-121, 1992a.

Myneni, R B., B. D. Ganapol, and G Asrar, Remote sensing of vegetation canopy photosynthetic and stomatal conductance efficiencies, Remote Sensing Environ., 42, 217-238, $1992 \mathrm{~b}$.

Olsson, L., and L Eklund, Fourier series for analysis of temporal sequences of satellite sensor imagery, Int. J. Remote Sensing, 15, 3735-3741, 1994.

Pinty, B, and M.M. Verstraete, GEMI A non-linear index to monitor global vegetation from satellites, Vegetatio, 101,15 20, 1992.

Potter, C. S., J. T. Randerson, C. B. Field, P. A. Matson, P. M 
Vitousek, H. A. Mooney, and S. A. Klooster, Terrestrial ecosystem production: A process model based on global satellite and surface data, Global Biogeochem Cycles, 7, 811-842, 1993.

Prince, S.D. and S.N. Goward, Evaluation of the NOAA/NASA Pathfinder AVHRR Land Data Set for global primary production modeling, Int. J. Remote Sensing, 17, 217-221, 1996.

Privette, J.L., R.B. Myneni, C.J. Tucker, and W.J. Emery, Invertability of a 1-D discrete ordinates canopy reflectance model, Remote Sensing Environ., 48, 89-105, 1994.

Privette, J.L., W.J. Emery, R.B. Myneni, and D.S. Schimel, Inversion of a vegetation reflectance model with NOAA AVHRR data, Remote Sensing Environ., in press, 1996.

Qin, W.-H., Modeling bidirectional reflectance of multicomponent canopies, Remote Sensing Environ., 46, 235-245, 1993.

Roujean, J.-L., and F.-M. Breon, Estimating PAR absorbed by vegetation from bidirectional reflectance measurements, $R e$ mote Sensing Environ., 51, 375-384, 1995.

Ross, I.U., The Radiation Regime and Architecture of Plant Stands, Dr. W. Junk, The Hague, Netherlands, 1981.

Ruimy, A., B. Saugier, and G. Dedieu, Methodology for the estimation of terrestrial net primary production from remotely sensed data, J. Geophys. Res., 99(D3), 5263-5283 , 1994.

Running, S. W., R. R. Nemani. D. L. Peterson, L. E. Band, D. F. Potts, L. L. Pierce, and M. A. Spanner, Mapping regional forest evapotranspiration and photosynthesis by coupling satellite data with ecosystem simulation, Ecology, 70, 1090-1101, 1989.

Running, S., T.R. Loveland, E.R. Hunt, A remote sensing based vegetation classification logic for global land cover analysis, Remote Sensing Environ., 51, 39-48, 1995.

Schimel, D.S., Terrestrial ecosystems and the carbon cycle, Global Change Biol., l, 77-91, 1995.

Sellers, P. J., J. A. Berry, G. J. Collatz, C. B. Field, and F. G. Hall, Canopy reflectance, photosynthesis, and transpiration, III, A reanalysis using improved leaf models and a new canopy integration scheme, Remote Sensing Environ., 42, 187-216, 1992.

Sellers, P.J., and D.S. Schimel, Remote sensing of the land biosphere and biogeochemistry in the EOS era: Science priorities, methods and implementation - EOS land biosphere and biogeochemical panels, Global Planet. Change, 7, 279-297, 1993.

Sellers, P.J., C.J. Tucker, G.J. Collatz, S.O. Los, C.O. Justice, D.A Dazlich, and D.A. Randall, A Global $1^{\circ}$ by $1^{\circ}$ data set for cli- mate studies, 2, The generation of global fields of terrestrial biophysical parameters from the NDVI, Int. J. Remote Sensing, 15, 3519-3545, 1994.

Spath, H., Cluster Analysis Algorithms, Ellis Horwood, West Sussex, England, 1980.

Townshend, J.G.R., C.O. Justice, D. Skole, J.-P. Malingreau, J. Cihlar, J. Teillet, F. Sadowski, and S. Ruttenberg, The $1-\mathrm{km}$ AVHRR global data set: Needs of the International Geosphere Biosphere Program, Int. J. Remote Sensing, 15, 3319-3332, 1994.

Verhoef, W., Light scattering by leaf layers with application to canopy reflectance modeling: The SAIL model, Remote Sensing Environ., 16, 125-141, 1984.

Verhoef, W., Earth observation modeling based on layer scattering matrices, Remote Sensing Environ., 17, 165-178, 1985.

Walthall, C.J., J.M. Norman, J.M. Welles, G. Campbell, and B.L. Blad, Simple equation to approximate the bidirectional reflectance from vegetated canopies and bare soil surfaces, Appl. Opt., 24, 383-387, 1985.

B. H. Braswell and B. Moore III, Institute for the Study of Earth, Oceans, and Space, University of New Hampshire, Durham, NH 03824. (e-mail: rob.braswell@unh.edu; b.moore@unh.edu)

D. S. Schimel and E. W. Sulzman, National Center for Atmospheric Research, P.O. Box 3000, Boulder, CO 80307-3000. (email: schimel@ncar.ucar.edu; sulzman@ncar.ucar.edu)

J. L. Privette, Department of Geography, University of Maryland, College Park, MD 20771. (email: jeff.privette@gsfc.nasa.gov)

W. J. Emery, Colorado Center for Astrodynamics Research, University of Colorado, Boulder, CO 80309. (email: emery@frodo.colorado.edu)

A. T. Hudak, Center for the Study of Earth from Space, University of Colorado, Boulder, CO 80309. (email: hudak@hypatia.colorado.edu)

(Received December 20, 1995; revised June 18, 1996; accepted June 27, 1996) 